\title{
Is Melioidosis a One Health-Neglected Disease in Iran?
}

\author{
Zahra Baradaran-Seyed $^{1 *}$ \\ ${ }^{1}$ Razi Vaccine and Serum Research Institute, Agricultural Research, Education and Extension Organization, Karaj, Iran \\ Corresponding Author: Zahra Baradaran-Seyed, DVM, MPH, PhD, Assistant Professor, Razi Vaccine and Serum \\ Research Institute, Agricultural Research, Education and Extension Organization, Karaj, Iran. Tel: +98-26-34570038; \\ Fax: +98-26-34552194, Email: z.bseyed@rvsri.ac.ir
}

Received March 1, 2020, 2019; Accepted July 4, 2020; Online Published July 25, 2020

\begin{abstract}
According to the several scientific resources, Iran is considered to be among the melioidosis-endemic regions of the world; this is in stark contrast to the domestic stance in Iran, where the risk of melioidosis is speculated only as an emerging infectious disease in a nonendemic area. Recently, devastating flash floods has occurred in the most provinces of Iran; the change of soil structure may facilitate the cultivation of bacteria in the upper layers of the ground, consequently causes exposure and re-emergence of the disease. Considering previous isolation and identification of Burkholderia mallei, Burkholderia Pseudomallei, and Burkholderia cepacia complex from human, animal, and environment samples in Iran, it is urgently necessary to upgrade and equip infrastructures to identify and distinguish between pathogenic Burkholderia and commensals in the context of the One Health surveillance system. In the present perspective, the history of melioidosis in the country is presented to attract attention to the negligence of disease over the last four decades.

Keywords: Burkholderia pseudomallei, Travel Medicine, Sentinel Surveillance
\end{abstract}

Citation: Baradaran-Seyed Z. Is melioidosis a one health-neglected disease in Iran? Int J Travel Med Glob Health. 2020;8(3):93-95. doi:10.34172/ ijtmgh.2020.16.

\section{Introduction}

The International Association for Medical Assistance to Travelers has cited melioidosis as a travel risk in Iran. ${ }^{1}$ Even with sporadic reports, Iran is considered one of the few endemic areas according to the several scientific resources. ${ }^{2,3}$ Based on some insignificant documents, all dated back to the 1970s, the burden and distribution of disease in Iran, as an endemic country, have been estimated by Limmathurotsakul et al. ${ }^{3}$ This is in stark contrast to the domestic stance in Iran, where the risk of melioidosis is considered only as an emerging infectious disease in a non-endemic area. ${ }^{4}$ Because laboratories in nonendemic regions are not familiar or equipped to isolate and identify the pathogen, misidentification occurs repeatedly. ${ }^{2,3,5}$ Therefore, it is urgently necessary to upgrade and equip laboratory infrastructures to identify and distinguish between not only pathogenic burkholderia and commensals, but also other misidentified bacteria such as pseudomonas. In the present perspective, the history of melioidosis in the country is presented to attract attention to the negligence of disease in Iran.

\section{The History of Melioidosis in Iran}

Pseudomonas pseudomallei (also known as Burkholderia pseudomallei) was detected by researchers for the first time ever in 1967 at the Department of Animal Pathology of Razi Institute (Razi Vaccine and Serum Research Institute, RVSRI). ${ }^{6}$ The bacterium was isolated from the gray pus in lung abscesses of Saanen goats supplied by a nearby state-owned farm. In another case, sheep brought from the southern parts of Iran were diagnosed and confirmed through additional laboratory investigations. ${ }^{6}$ Only 2 years later, an outbreak of melioidosis in two horses and one mule was reported at RVSRI. This time, the isolated organism was also confirmed by the Walter Reed Army Institute. ${ }^{6,7}$ Mice and rats were also trapped for further investigation, but test results came back negative and the origin and epidemiology of the disease remained unknown. ${ }^{6}$ These reports continued with the outbreak of melioidosis in France where the hypothesis of the origin seemed strongly linked to the import of a panda from an infected geographical site as well as two Iranian horses offered to the wife of the president of France in $1971 .^{8}$ Consequently, in 1975, Pourtaghva et al investigated the mud of northern rice fields and isolated 19 Pseudomonas pseudomallei (types I and II) out of 157 samples. ${ }^{9}$ This study led them to consider at least some regions of the country as the suitable ecological niche for B. pseudomallei. Ultimately, the final nail in the

Copyright $($ C 2020 The Author(s). This is an open-access article distributed under the terms of the Creative Commons Attribution License (http:// creativecommons.org/licenses/by/4.0), which permits unrestricted use, distribution, and reproduction in any medium, provided the original work is properly cited. 
coffin was human pulmonary melioidosis identified in Iran in $1977 .{ }^{10}$ It seems that all mentioned outbreaks ended in a popular international belief that Iran is an endemic region despite the four-decade waiver of domestic research studies. ${ }^{2}$, ${ }^{3}$ To the best of the author's knowledge and based on a search of multiple scientific databases, no study has been carried out with the aim of detecting the pathogen in the environment, animals, and humans in Iran in the last four decades. The only documented case over these years was one of bacteremic melioidosis in an Iranian male. ${ }^{4}$ The case study did mention that it was the first report of bacteremic melioidosis in the country and occurred in an Iranian traveler to Southeast Asia, an endemic region of disease. ${ }^{4}$ Fever and chills developed on the last day of the patient's trip to Malaysia and Thailand. Then, B. pseudomallei was isolated from his blood sample and bronchoalveolar lavage when he was admitted to a hospital in Tehran in $2011 .^{4}$

\section{Other Pathogenic Burkholderia in Iran}

To date, more than 70 species of bacteria have been identified in the family of burkholderiaceae, although most of them are non-pathogenic microorganisms. ${ }^{11}$ Among few pathogenic bacteria, Burkholderia mallei, the causative agent of glanders, and Burkholderia cepacia complex (BCC) have also been reported in Iran. ${ }^{7}$ According to the World Organization for Animal Health (OIE), glanders, an equine infectious disease caused by $B$. mallei, is on the list of notifiable diseases. ${ }^{12}$ Moreover, the Centers for Disease Control and Prevention (CDC) listed B. mallei and B. pseudomallei in category B of potential bioterrorism agents/diseases. ${ }^{13}$ Burkholderia mallei is believed to have been prevalent in Iran in $1919 .{ }^{14}$ The mallein diagnostic test was conducted to identify the infection in a military equine population as early as the 1920 s. ${ }^{14}$ Between 1973 and 1993, there was no report of the disease. ${ }^{7,14}$ It seems more to have been controlled for a while longer than to have been fully eliminated; from that period until now, sporadic cases or outbreaks have been reported repeatedly in the equine population. ${ }^{7} 14$ Moreover, the outbreak of glanders in a captive Amur tiger and African lions that occurred in a zoo in 2010 was attributed to the consumption of donkey meat imported from Iraq. ${ }^{7}{ }^{14}$ Indeed, a new era of Iran's challenges to control glanders began following the war and unrest in the neighboring country of Iraq that caused serious damage to the infrastructures of human and animal health sectors.

Another bacteria, BCC, comprises more than 20 different species. ${ }^{11}$ They are well-known opportunistic pathogens in patients with underlying medical conditions like cystic fibrosis. $^{11,15}$ B. cepacia genomovar I and III have already been identified in Iranian cystic fibrosis patients, ${ }^{16}$ and non-identified BCC has been cultivated from hospital environments and agricultural samples. Although there have been several reports of the pathogenicity of BCC in the animal kingdom during the past few years, ${ }^{17}$ there is no published study from Iran.

\section{The Necessity of a One Health Approach}

What is most striking in reviewing the first reports of melioidosis in the world is that the initial identification of infections in animals, especially small ruminants, resembled cases in Iran. ${ }^{5}$ Due to the higher interface of animals with the environment, disease or infection is detected sooner in the animal kingdom. In fact, melioidosis is one of the diseases with which susceptible animals are sentinel species of human populations - a canary in a coalmine. ${ }^{5}$ Heretofore, the occurrence of melioidosis in a wide range of domestic and wild animals was reported. Against glanders that is a highly contagious zoonotic disease, zoonotic cases of melioidosis have rarely occurred, and the common sources usually pose the risk to both animals and humans ${ }^{5}$. Therefore, the existence of saprophyte $B$. pseudomalle $i$ in the environment or reports of animal cases can be a wake-up call for public health. Irrigation and agricultural interventions have played a role in the re-emergence of melioidosis. ${ }^{2,5}$ Furthermore, there have been previous reports that animals and humans have contracted the disease following floods. ${ }^{2}$ Recently, devastating flash floods have occurred in most provinces of Iran; the changing of the soil structure may facilitate the cultivation of bacteria in the upper layers of the ground, consequently causing exposure and re-emergence of the disease. Because of the interface of humans, animals, and environment health in the epidemiology of pathogenic Burkholderia, a One Health approach is required to deal with pathogens including, but not limited to, B. pseudomallei.

\section{Conclusion}

Due to the proven threats of pathogenic Burkholderia at the human-animal-ecosystem interface, a sentinel surveillance system of these agents should be implemented in a One Health tripartite collaboration framework. Four decades of negligence of melioidosis in some ways parallel the controversial issues related to the control of equine glanders in the country. Recent identification of pathogenic BCC in Iranian patients and animal cases of BCC infection in other countries ${ }^{7,15,17}$ all prove beyond any doubt the urgent necessity to upgrade and equip infrastructures to identify and distinguish between pathogenic Burkholderia and commensals in the context of a One Health surveillance system. ${ }^{2,7,15}$

\section{Conflict of Interest Disclosures}

The author declares no conflicts of interest.

\section{Ethical Approval}

Not applicable.

\section{Funding/Support}

None.

\section{References}

1. International Association for Medical Assistance to Travellers (IAMAT). Iran for Specific Travellers: Melioidosis. https://www. iamat.org/country/iran/risk/melioidosis. Published 2020.

2. Currie BJ, Dance DA, Cheng AC. The global distribution of Burkholderia pseudomallei and melioidosis: an update. Trans R Soc Trop Med Hyg. 2008;102 Suppl 1:S1-4. doi:10.1016/s00359203(08)70002-6.

3. Limmathurotsakul D, Golding N, Dance DA, et al. Predicted global distribution of Burkholderia pseudomallei and burden 
of melioidosis. Nat Microbiol. 2016;1(1). doi:10.1038/ nmicrobiol.2015.8.

4. Darazam IA, Kiani A, Ghasemi S, et al. Melioidosis: It is not Far from here. Tanaffos. 2011;10(4):64-68.

5. Limmathurotsakul D, Dance DA. Global Burden and Challenges of Melioidosis. Basel: Multidisciplinary Digital Publishing Institute (MDPI); 2019.

6. Baharsefat $M$, Amjadi AR. Equine melioidosis in Iran. Arch Razi Inst. 1970;22(1):209-213. doi:10.22092/ari.1970.108685.

7. Arefnejad M, Tajzadeh P, Barjesteh A. A history of Burkholderiacaused infections in Iran. J Paramed Sci Rehabil. 2013;2(2):54-59. doi:10.22038/jpsr.2013.1714. [Persian].

8. Galimand M, Dodin A. Repartition de Pseudomonas pseudomallei en France et dans le monde la melioidose. Bull Soc Vet Prat de France. 1982;66:651-657.

9. Pourtaghva $M$, Machoun A, Dodin A. [Demonstration of Pseudomonas pseudomallei (Whitmore's bacillus) in the mud of Iranian ricefields (author's transl)]. Bull Soc Pathol Exot Filiales. 1975;68(4):367-370

10. Pourtaghva M, Dodin A, Portovi M, Teherani M, Galimand M. [1 st case of human pulmonary melioidosis in Iran]. Bull Soc Pathol Exot Filiales. 1977;70(2):107-109.

11. Sawana A, Adeolu M, Gupta RS. Molecular signatures and phylogenomic analysis of the genus Burkholderia: proposal for division of this genus into the emended genus
Burkholderia containing pathogenic organisms and a new genus Paraburkholderia gen. nov. harboring environmental species. Front Genet. 2014;5:429. doi:10.3389/fgene.2014.00429.

12. World Organization for Animal Health (OIE). OIE-Listed Diseases, Infections and Infestations in Force in 2020. OIE; 2020. https://www.oie.int/animal-health-in-the-world/oie-listeddiseases-2020/.

13. Centers for Disease Control and Prevention (CDC). Bioterrorism Agents/Diseases. CDC; 2020. https://emergency.cdc.gov/agent/ agentlist-category.asp.

14. Akbarein H, Bahonar AR, Dabbagh Moghaddam A, Bolouki Z, Hosseini Shokouh SJ. Glanders, a new vision on an old biological weapon. Ann Mil Health Sci Res. 2012;10(2):143-162. [Persian].

15. Soltan Dallal MM, Telefian CF, Hajia $M$, et al. Identification and molecular epidemiology of nosocomial outbreaks due to Burkholderia cepacia in cystic fibrosis patients of Masih Daneshvary Hospital, Iran. J Prev Med Hyg. 2014;55(1):27-30.

16. Eram SM, Behzadian Nejad Q, Khatami GR, Nafissi N. Detection of Burkholderia cepacia complex in patients with cystic fibrosis. Tanaffos. 2004;3(9):47-52.

17. Berriatua E, Ziluaga I, Miguel-Virto C, et al. Outbreak of subclinical mastitis in a flock of dairy sheep associated with Burkholderia cepacia complex infection. J Clin Microbiol. 2001;39(3):990-994. doi:10.1128/jcm.39.3.990-994.2001. 